\title{
STUDY ON CORRELATION BETWEEN FIRE FIGHTING TIME AND FIRE LOSS IN URBAN BUILDING BASED ON STATISTICAL DATA
}

\author{
Deyong WANG, Lu LU, Jiping ZHU, Jiajie YAO, Yunlong WANG, Guangxuan LIAO \\ State Key Laboratory of Fire Science, University of Science and Technology of China, Hefei 230026, China
}

Received 18 Sep 2013; accepted 14 Nov 2013

\begin{abstract}
In this paper, the correlation between fire fighting time and fire loss (burned area of urban building) based on fire statistical data in Jiangxi Province (China) from 2000 to 2010 was studied. The results showed the probability distribution of fire fighting time met lognormal distribution. In the probability density function, the expectation of the distribution represents the average level of fire fighting time. We found the average fighting time of warehouse and workshop fires were higher than the average level of whole building fires. In addition, the probability distribution of the burned area in each fire fighting time interval also followed power function, which was valid in the case of the fire fighting time within 4 hours. Furthermore, the absolute value of the exponent of the function is positively correlated with the small-scale fires and negatively with the large-scale fires. The value decreased with the increase of the fire fighting time, indicating that the fire control ability became poor with longer fire fighting time. Also, the fire control ability in residential waned fastest as the fighting time increased, and the ability in warehouse waned slowest.
\end{abstract}

Keywords: building fire, fire fighting time, fire statistical data, burned area, lognormal distribution, power law function.

\section{Introduction}

As the economics develops fast, the number of urban buildings increases as well. This inevitably caused more fires than in the past, which brought severe casualty and property loss (Chow, C. L., Chow, W. K. 2009; Cyras et al. 1999; Shi et al. 2013). For example, 11,393 fires with an estimated damage of 2,175 million Litas occurred in Lithuania in 1997. 227 persons perished in fires, 15 children among them. 134 people were wounded (Cyras, Griskevicius 2001). It's significant to study the characteristics of fire rescue and fire loss in urban building fire prevention.

Previous researchers have done relatively deep study on fire loss. There is lots of research work stated that fire loss followed the distribution of power law (Song et al. 2003; Ramachandran 1998, 1972, 1975; Shpilberg 1977). Fontana et al. (1999) provided tabulated distributions of the number of fires and fire loss for different occupancies based on 40,000 building fires in Switzerland between 1986 and 1995. Burned area, which reflects both building characteristics and position of fire sources, is usually used as an index of fire loss (Sardqvist, Holmstedt 2000).

The effectiveness of fire brigades is directly relevant to fire loss and reflects the ability of city to deal with disasters. It can be considered that fire response time (including ignition time, alarm time, reach time, and fire fighting time.) reveals the effectiveness of fire rescue. There is a close relationship between fire loss and fire response time. Lu et al. (2013a) have studied the correlation between the burned area and fire reach time and found the frequency of fire attendance time meet power-low distribution. Sardqvist and Holmstedt (2000) studied the statistical data of 307 fires in non-residential buildings of London between 1994 and 1997. They found that fire fighting time increased almost linearly with burned area. However, the results of this research were limited due to the small samples size. Based on the previous study, we inferred that there should be similar relationship between fire fighting time and burned area. Fire fighting time affected and determined the duration of fires and the fire loss in some way. The type of fire sites significantly affects both burned area and fire fighting time. However, there is little research on this correlation. So it's essential to study the law of fire loss in different fire sites.

In this paper, the correlation between burned area and fire fighting time was investigated by using the fire statistical data in Jiangxi Province of China from 2000 to 2010. And the effects of different building types on the correlation are further analyzed.

Corresponding author: Jiping Zhu

E-mail: jpzhu@ustc.edu.cn 


\section{Statistical data}

\subsection{Data description}

Jiangxi Province is located at the southeast of China and lower reaches of Yangtze River. The average temperature is about $18{ }^{\circ} \mathrm{C}$. It covers 16.69 square kilometers areas with a population of $4,503.93$ million (2012). On the one hand, the population of Jiangxi Province is relatively concentrated. The development of the cities in Jiangxi Province is relatively balanced, like many cities in China, with the similar urban structure and economic development level. On the other hand, Lu et al. (2013a) studied the statistical law of fire attendance time and analyzed the correlation between fire attendance time and burned area based on the urban fire statistical data both of Japan from 1995 to 2003 and Jiangxi Province from 2000 to 2010. It was found that both Japan and Jiangxi Province have the same law with the different parameters due to the different social economic factor. Based on this result, we believe that the fire fighting time in different areas will also have the same law, and the social economic factor can affect the parameters, so we only chose the the data from the Jiangxi Province to avoid the influence of the social economic factor. In the future, we can further analysis the influence of the social economic factor on the correlation between fire fighting time and fire loss, using more data from the different provinces in China.

The fire statistical data was provided by the Fire Bureau of Jiangxi Province. The statistical data contain 20,630 fires between 2000 and 2010. The data has recorded the dispose situation and fire loss in detail. Each record contains the following factors:

- Fire property: ignition time, fire site, cause of fire;

- Monetary loss: burned area, casualties and economic loss;

- Fire situation: building structure, building type, fireproof grade;

- Fire response time: alarm time, reach time, control time, and extinguish time;

- Fire fighting time is defined as the difference between reach time and extinguish time.

In this paper, the parameters of burned area and fighting time were focused. Studying the total statistical data in Jiangxi Province, we found that the number of fires with burned area less than $2,000 \mathrm{~m}^{2}$ accounts for $99.8 \%$. Then, the fires with fire fighting time less than 4 hours accounts for $98.3 \%$. Therefore, only the fires with burned area less than $2,000 \mathrm{~m}^{2}$ and fire fighting time less than 4 hours were considered.

The data was collected for urban building fires. Based on the function of these buildings, we divided the type of fire sites into seven kinds containing dwelling, market place, public amenities, restaurant, hotel, workshop and warehouse. Other urban fires including vehicle, dustbin and plant open-airframe are excluded. Therefore, the available data in this study are 15,491 fires.

The proportion of the data set is shown in the appendix.

\subsection{Analysis of data error}

It is essential to eliminate human error to reveal the statistical law of fires. Lu et al. (2013a) have claimed that there were three kinds of human errors in fire statistical data: the first one is caused by the discretization of the record value; the second one is subjective deviation of fire statistics personnel; the third one is measurement error when fire officers record data. In this paper, we use the same method to deal with the statistical data.

The minimum record unit of fire fighting time and burned area is $1 \mathrm{~min}$ and $1 \mathrm{~m}^{2}$, respectively. Therefore, we chose $1 \mathrm{~min}$ as the statistical interval size for fire fighting time frequency statistics, and $1 \mathrm{~m}^{2}$ for burned area. Meanwhile, the frequency numbers of burned area at integral multiples of $10 \mathrm{~m}^{2}$ are higher than that at other values and fire fighting time at integral multiples of $5 \mathrm{~min}$ are higher than that of other values (Fig. 1a). We use Adjacent-Averaging smooth method with ten points window size to process the burned area data and five points window size is used to process fire fighting time data. Imitative effect of results is better after eliminating the error, as is shown in Figure 1b. The fitting coefficient of normal logarithms distribution changed from 0.90647 to 0.99548 . $\mathrm{R}^{2}$ is employed as the indicator of the good-

a)

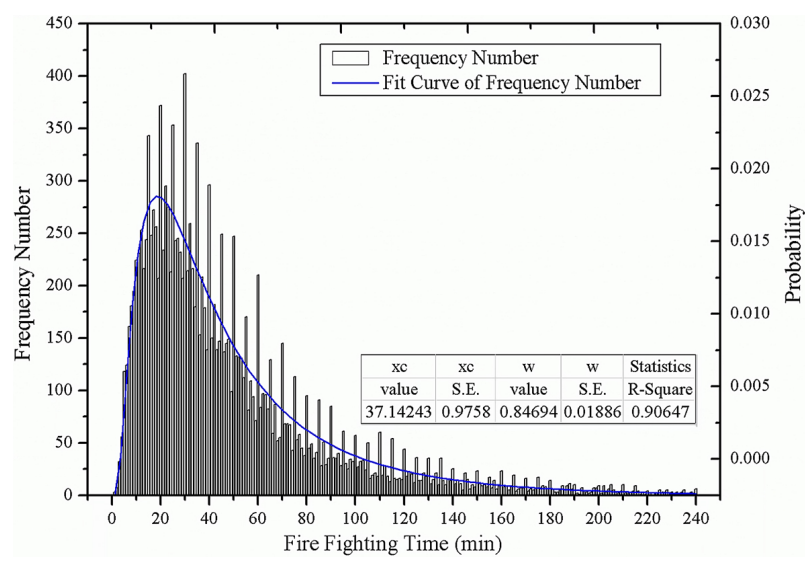

b)

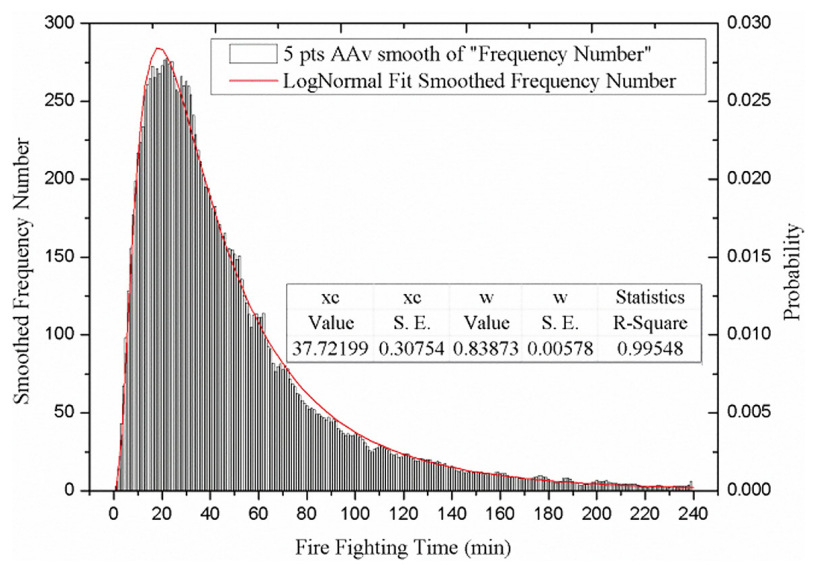

Fig. 1. Frequency histogram for urban fire data of Jiangxi Province from 2000 to 2010 along with the lognormal distribution curve: (a) Original data, (b) Five-points smooth data 
ness-of-fitting. In most studies on fire statistics, the $R^{2}$ is generally not too high. The possible reason may lies in that the sample capacity is small. For example, the highest $R^{2}$ value in Sardqvist's and Holmstedt's study (2000) is 0.61 . And Challands (2010) also confirm a linear fit with $R^{2}=0.55$ in his paper. Based on the previous study, we use 0.7 as an empirical threshold in most of cases in this paper, without any theoretical basis.

\section{Statistical law of fire fighting time and burned area}

\subsection{Statistical law of fire fighting time}

The frequency distribution of fire fighting time was shown in Figure 1. It has shown that the human error caused the fire fighting time gathered at the groups of integral multiples of $5 \mathrm{~min}(5 \mathrm{~min}, 10 \mathrm{~min}, 15 \mathrm{~min}$, and so on) in Figure 1a. After smoothing the curve by every 5 min shown in Figure 1b, the fitting coefficient of lognormal distribution is raised from 0.90647 to 0.99548 . The previous study showed that the fire times and fire reach time followed lognormal distribution, so we used lognormal distribution (Eqn (1)) to fit the fire fighting time of all the fires. And the probability density function of the lognormal distribution was fitted as Eqn (1), where $R^{2}=0.99548, x_{c}=37.72199$ and $\omega=0.83873$ :

$$
f\left(t_{f}, x_{c}, w\right)=\frac{1}{\sqrt{2 \pi} \cdot \omega \cdot t_{f}} \exp \left[-\frac{\left(\ln \left(t_{f} / x_{c}\right)\right)^{2}}{2 \omega^{2}}\right] .
$$

The fitting result shows the frequency modeled as lognormal distribution with fighting time. And the average fighting time is about $38 \mathrm{~min}$.

\subsection{Correlation between fire fighting time and burned area}

When studying the correlation between fire fighting and burned area, it is helpful to set the fighting time into several groups. In this paper, we set the separation of each group as $20 \mathrm{~min}$. The small separation is unable to assure the adequacy of data in each group, while the large one causes few groups. Fire fighting time intervals mark as $N=1,2, \ldots, 12=[1,20],[21,40], \ldots,[221-240]$. Figure 2 illustrated burned area probability distribution and its fitting curves: (a) $N=1$, (b) $N=3$, (c) $N=5$, (d) $N=10$.

In the double logarithmic coordinates, power function fitting curve performed as a line. This shows that burned area follows power law in the different sections. Meanwhile, the slope of the fitting curve increases with the increase of fire fighting time. The slope represents the fighting efficiency: the smaller the slope, the higher efficiency, and the better fire control ability.

Burned area is denoted by $X$, for each $N$, the probability of $X$ corresponds to the power function distribution. Thus, the probability distribution of burned area at each $N$ is defined as:

$$
p\left(X=x_{i} \mid N\right)=A(N) \cdot x_{i}^{B(N)},
$$

where: $p\left(X=x_{i} \mid N\right)$ is the probability value of burned
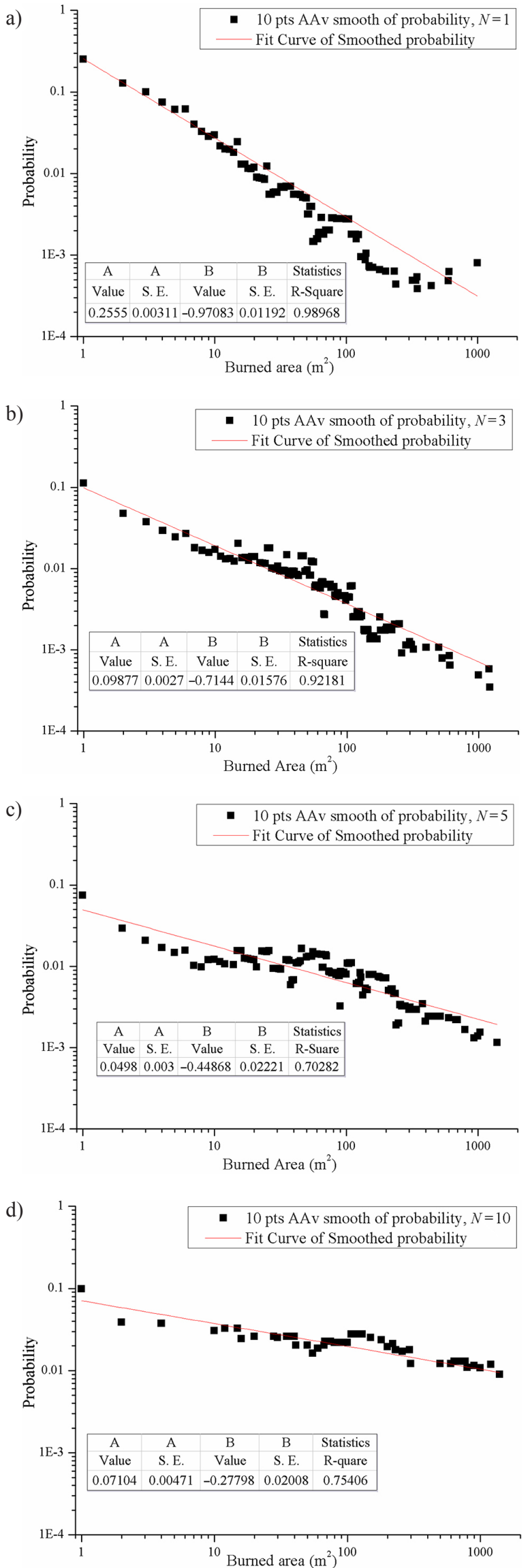

Fig. 2. Probability-burned area distribution and its fitting curves of different time interval: (a) $N=1$, (b) $N=3$, (c) $N=5$, (d) $N=10$ 
area with $X$ while fire fighting time interval is $N ; X$ is the discrete random variable of the burned area; $x_{i}$ is the possible value of $X, i=1,2,3, \ldots, 2,000 ; t_{f}$ is the fire fighting time; and $A(N), B(N)$ are the coefficients related to the fire fighting time interval.

Table 1 shows all fitting coefficients of each dataset with the fire fighting time from $1 \mathrm{~min}$ to $240 \mathrm{~min}$. We presume that the scope of application of the power law distribution is the case of the fire fighting time less than $220 \mathrm{~min}$. Furthermore, we find that $A(N)$ can be exponentially fitted with fire fighting time and $B(N)$ can be linear fitted with fire fighting time very well, as shown in Figures 3 and 4, respectively.

Table 1. Specific fitting coefficients between the burned area and its probability under each fire fighting time interval

\begin{tabular}{ccccc}
\hline $\begin{array}{c}\text { Fighting } \\
\text { time }\end{array}$ & $\begin{array}{c}\text { Sample } \\
\text { number }\end{array}$ & $R^{2}$ & $A(N)$ & $B(N)$ \\
\hline $1-20$ & 3,743 & 0.98968 & 0.25550 & -0.97083 \\
\hline $21-40$ & 4,879 & 0.98211 & 0.14395 & -0.82172 \\
\hline $41-60$ & 2,887 & 0.92181 & 0.09877 & -0.71442 \\
\hline $61-80$ & 1,534 & 0.81090 & 0.06003 & -0.52591 \\
\hline $81-100$ & 867 & 0.70282 & 0.04980 & -0.44868 \\
\hline $101-120$ & 538 & 0.71691 & 0.04507 & -0.39289 \\
\hline $121-140$ & 380 & 0.80664 & 0.04629 & -0.33359 \\
\hline $141-160$ & 238 & 0.64624 & 0.04308 & -0.25464 \\
\hline $161-180$ & 173 & 0.53114 & 0.03675 & -0.16641 \\
\hline $181-200$ & 112 & 0.75406 & 0.07104 & -0.27798 \\
\hline $201-220$ & 87 & 0.61290 & 0.04260 & -0.14401 \\
\hline $221-240$ & 53 & 0.01028 & 0.05488 & -0.08774 \\
\hline Total & 15,491 & - & - & - \\
\hline
\end{tabular}

Based on this analysis, the burned area $X$ of fires in Jiangxi Province meets the following equations, in the case of the fire fighting time less than $220 \mathrm{~min}$.

$$
\left\{\begin{array}{l}
p\left(X=x_{i} \mid N\right)=A(N) \cdot x_{i}^{B(N)} \\
A(N)=0.25372 \times N^{-0.86236}, \quad(N \leq 11) . \\
B(N)=0.07828 N-0.92886
\end{array}\right.
$$

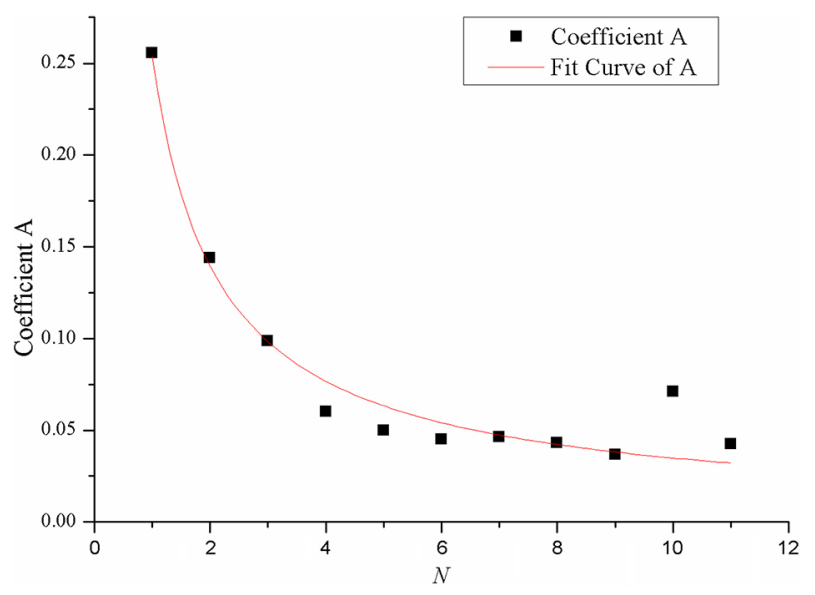

Fig. 3. Regression curve of coefficient $A$ of power law and fire fighting time interval

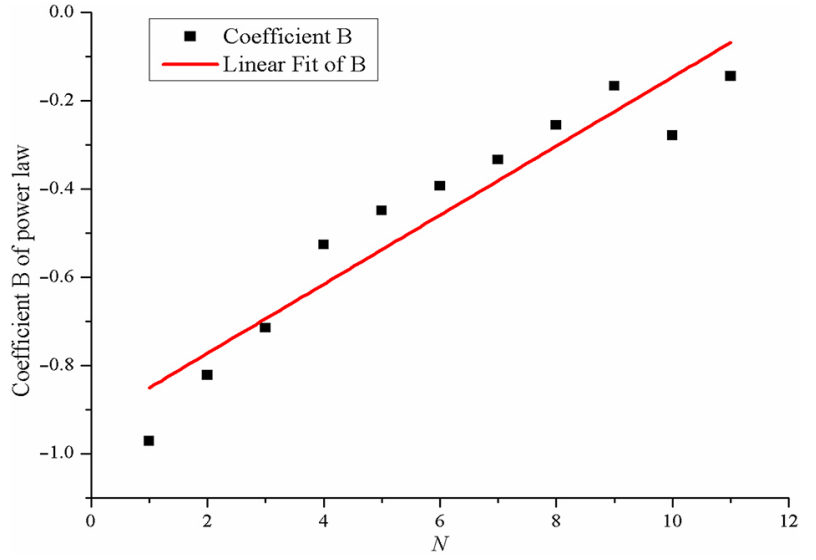

Fig. 4. Regression curve of coefficient $B$ of power law and fire fighting time interval

\section{Statistical analysis of burned area and fire fighting time in different types of fire site}

\subsection{Analysis of fire fighting time for different types of fire site}

Correspondence analysis (CA) is an analyzing method, which is based on multiple variable statistics. And this has been widely applied in market segmentation, geology research and computer engineering (Diana, Pronello 2010; Cakir et al. 2006; Beh et al. 2011). In this paper, we use this method to study the differences of fire fighting time for different sites. Contingency table of fire site and fighting time is summarized in Table 2. And correspondence analysis of fire site and fighting time is shown in Figure 5. Fire fight time increases from left to right in the abscissa axis: this indicates the left part leans to fires with shorter fire fighting time and the right part leans to fires with longer time. There are several characteristics in different fire sites. As shown in Figure 5, similarities of sites are analyzed by law of cosines (Jacques 1993; Sourial et al. 2010). Market place, public amenities and restaurants have the similar outline. And these sites are closer to fighting time 1-40. Workshop and warehouse tend to near the outline with longer fighting time, due to more combustion in these sites cause fire spreading fast

Table 2. Contingency table of fire site and fire fighting time

\begin{tabular}{|c|c|c|c|c|c|}
\hline \multirow{2}{*}{ Site } & \multicolumn{4}{|c|}{ FFT (min) } & \multirow{2}{*}{ Total } \\
\hline & $1-40$ & $41-80$ & $81-120$ & $120-240$ & \\
\hline Dwelling & 4,479 & 2,520 & 768 & 492 & 8,259 \\
\hline $\begin{array}{l}\text { Market } \\
\text { place }\end{array}$ & 582 & 180 & 64 & 49 & 875 \\
\hline $\begin{array}{l}\text { Public } \\
\text { amenities }\end{array}$ & 161 & 44 & 11 & 6 & 222 \\
\hline Restaurant & 278 & 48 & 9 & 3 & 338 \\
\hline Hotel & 127 & 38 & 4 & 0 & 169 \\
\hline Warehouse & 461 & 352 & 142 & 151 & 1,106 \\
\hline Workshop & 1,689 & 1,058 & 358 & 311 & 3,416 \\
\hline Total & 7,777 & 4,240 & 1,356 & 1,012 & 14,385 \\
\hline
\end{tabular}




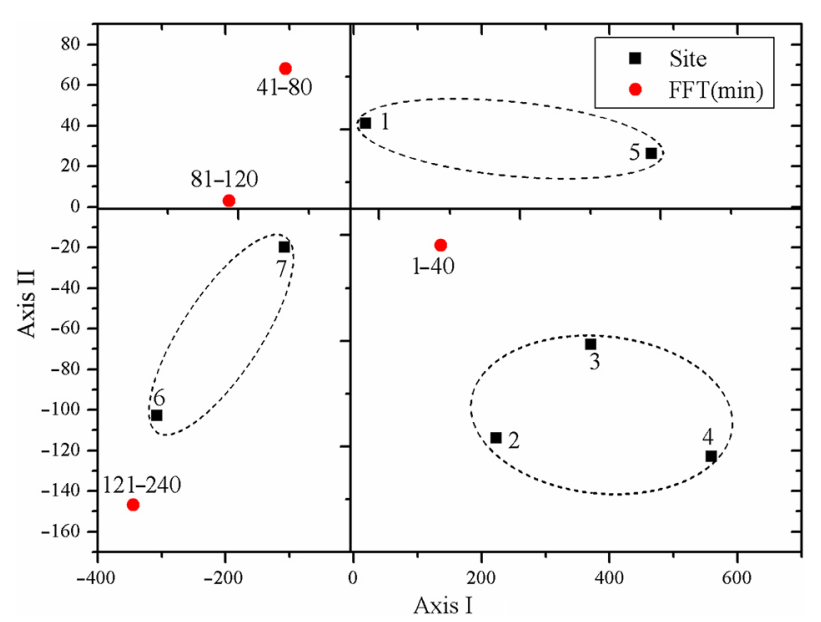

Fig. 5. Correspondence analysis of fire fighting time and fire site. Building categories: 1 - Dwelling, 2 - Market place, 3 Public amenities, 4 - Restaurant, 5 - Hotel, 6 - Warehouse, 7 -Workshop

(Holborn et al. 2002). Table 3 shows the expectation of average fighting time. We find that (i) average fighting time of workshop and warehouse is higher than the average fighting time of city fires; (ii) the value of dwelling is close to the average level of cities.

Table 3. Parameters of logarithm distribution with different fighting time

\begin{tabular}{lccc}
\hline \multicolumn{1}{c}{ Type of Site } & $x_{c}$ & $\omega$ & $R^{2}$ \\
\hline Dwelling & 38.69013 & 0.81276 & 0.99239 \\
\hline Marketplace & 29.33344 & 0.84573 & 0.96429 \\
\hline Public amenities & 30.09455 & 1.06176 & 0.64384 \\
\hline Restaurant & 26.74588 & 0.81402 & 0.83909 \\
\hline Hotel & 27.59172 & 0.83422 & 0.48035 \\
\hline Warehouse & 51.63392 & 0.87444 & 0.94269 \\
\hline Workshop & 43.15001 & 0.82676 & 0.98308 \\
\hline
\end{tabular}

\subsection{Analysis of burned area for different types of fire site}

Figure 6 shows a two dimension CA curves of burned area and fire site. Contingency table of fire site and burned area is summarized in Table 4. The abscissa axis represents burned area. By applying the law of cosines, market places, public amenities and restaurants have the similar outline, when the dwelling and hotel share the similar outline. The burned area is determined by the building structure and characteristics of combustion (Challands 2010). In addition, the warehouse and workshop fires lean to have relatively large burned area.

\section{Correlation between burned area and fire fighting time}

We studied the probability distribution of burned area with the fire fighting time less than $240 \mathrm{~min}$ for different fire sites. And we found the fitting result of restaurant and hotel fires became bad when the fire fighting time was

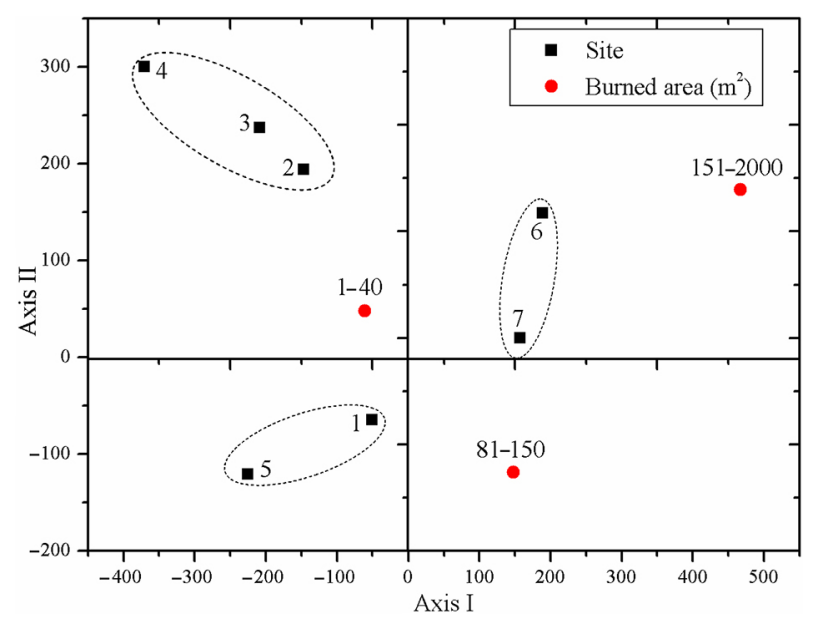

Fig. 6. Correspondence analysis of burned area and fire site. Building categories: 1 - Dwelling, 2 - Market place, 3 Public amenities, 4 - Restaurant, 5 - Hotel, 6 - Warehouse, 7 - Workshop

Table 4. Contingency table of fire site and burned area

\begin{tabular}{|c|c|c|c|c|c|}
\hline \multirow{2}{*}{ Site } & \multicolumn{4}{|c|}{ Burned area $\left(\mathrm{m}^{2}\right)$} & \multirow{2}{*}{ Total } \\
\hline & $1-40$ & $41-80$ & $81-150$ & $151-2000$ & \\
\hline Dwelling & 5,545 & 1,636 & 782 & 296 & 8,259 \\
\hline Marketplace & 690 & 101 & 48 & 36 & 875 \\
\hline $\begin{array}{l}\text { Public } \\
\text { amenities }\end{array}$ & 183 & 21 & 11 & 7 & 222 \\
\hline Restaurant & 303 & 27 & 5 & 3 & 338 \\
\hline Hotel & 119 & 41 & 8 & 1 & 169 \\
\hline Warehouse & 735 & 153 & 106 & 112 & 1,106 \\
\hline Workshop & 2,157 & 615 & 357 & 287 & 3,416 \\
\hline Total & 9,732 & 2,594 & 1,317 & 742 & 14,385 \\
\hline
\end{tabular}

larger than $40 \mathrm{~min}$.The data of dwelling, market place, public amenities, warehouse and workshop followed well with the power law distribution during 120 min. However, due to the lack of sample with the fire fighting time larger than $120 \mathrm{~min}$, it is difficult to fit linearly the burned area. Specific fitting coefficients are presented in Table 5.

Coefficients $B$ and $N$ follow linear relation as is shown in Figure 7. The slope of curve with dwelling fires is biggest, following by public amenities, market place, workshop and warehouse. As mentioned above, coefficient B represents the fire control ability. Therefore, Figure 7 also shows the level of fire control ability. We conclude that the fire control ability of residence fires decrease fastest and warehouse fires decrease slowest. Due to the limited number, fires in hotels and restaurants were not analyzed.

Coefficient $B$ in power law distribution demonstrates fire control ability. The absolute value decreases with the increasing of fighting time. That is to say, the fire control ability decreases with fighting time. Fire control ability is influenced by combustion characteristics, fire density, building structure and fire rescue force allocation. 


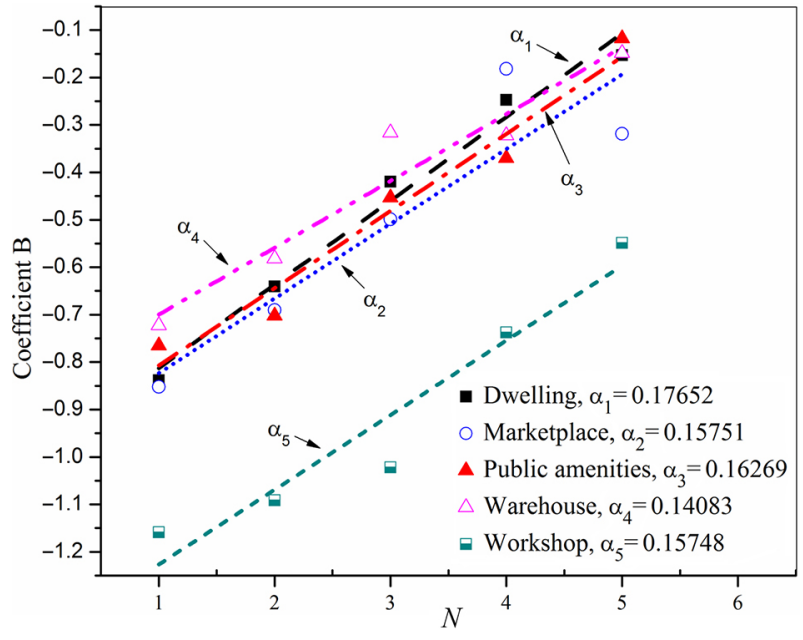

Fig. 7. Regression curve of coefficient $B$ of power law and fire fighting time interval $(\mathrm{N})$ with different sites

For dwellings, fire often occurs at bedrooms or kitchens where fire load is relative large (Robertson, Gross 1970; Sunil, Rao 1995). Furthermore, there are no automotive fire suppression system and smoke vent in these places. Fire can spread easily and fast and even reach flashover. That is why fire control ability decreased fastest for dwelling fires. Although the public amenities and market places have the similar level of fire load (Wei 2009), fire at these sites can be detected in the early period (Holborn et al. 2004) due to more attention was paid by professional management departments (Lu et al. 2013b). And there is automatic fire suppression system, so fire can be controlled at the early stage (Fontana et al. 1999). The warehouses, with more fire load (Barnett 1984) and large fire compartment, are easy to cause large burned area when fire occurs. These are possible factors which caused poor fire control ability.

\section{Conclusions}

Based on the urban building fire statistical data of Jiangxi Province (China) from 2000 to 2010, the following conclusions were obtained.

The probability distribution of fire fighting time of urban building fires satisfied a good lognormal distribution. The expectation of lognormal distribution represented the average level of fire fighting time. The fighting time was different for different site fire occurred. The average fighting time at warehouse and workshop was relatively long. The time at dwelling was close to the average fighting time of cities, however, the average fighting time at market place, public places, restaurants and hotels was shorter than the average fighting level of city fires.

The probability distribution of burned area in fire fighting time interval observed power function. Within in the bounds of the fire fighting time less than $220 \mathrm{~min}$, the exponent of power function can be taken as an indicator of fire control ability. We also found that absolute value
Table 5. Specific fitting coefficients between the burned area and its probability under each fire fighting time interval

\begin{tabular}{|c|c|c|c|c|}
\hline Site & $\begin{array}{c}\text { Fighting } \\
\text { time }\end{array}$ & $\begin{array}{l}\text { Sample } \\
\text { number }\end{array}$ & $R^{2}$ & $B(N)$ \\
\hline \multirow{6}{*}{ Dwelling } & $1-20$ & 1,819 & 0.97942 & -0.83861 \\
\hline & $21-40$ & 2,660 & 0.95571 & -0.64041 \\
\hline & $41-60$ & 1,630 & 0.81527 & -0.41989 \\
\hline & $61-80$ & 890 & 0.50924 & -0.28713 \\
\hline & $81-100$ & 482 & 0.33463 & -0.15264 \\
\hline & $101-120$ & 286 & 0.61039 & -0.22564 \\
\hline \multirow{6}{*}{ Market place } & $1-20$ & 310 & 0.98957 & -0.85220 \\
\hline & $21-40$ & 272 & 0.9512 & -0.69016 \\
\hline & $41-60$ & 129 & 0.72993 & -0.49910 \\
\hline & $61-80$ & 51 & 0.49205 & -0.37158 \\
\hline & $81-100$ & 38 & 0.94830 & -0.31893 \\
\hline & $101-120$ & 26 & 0.03208 & -0.03885 \\
\hline \multirow{5}{*}{$\begin{array}{l}\text { Public } \\
\text { amenities }\end{array}$} & $1-20$ & 81 & 0.99019 & -0.76477 \\
\hline & $21-40$ & 80 & 0.89304 & -0.70187 \\
\hline & $41-60$ & 30 & 0.94281 & -0.45335 \\
\hline & $61-80$ & 14 & 0.85899 & -0.36979 \\
\hline & $81-100$ & 11 & 0.93323 & -0.11736 \\
\hline \multirow{3}{*}{ Restaurant } & $1-20$ & 138 & 0.98254 & -0.58232 \\
\hline & $21-40$ & 139 & 0.92203 & -0.3791 \\
\hline & $41-60$ & 37 & 0.21835 & -0.19521 \\
\hline \multirow{3}{*}{ Hotel } & $1-20$ & 70 & 0.8929 & -0.4226 \\
\hline & $21-40$ & 57 & 0.82709 & -0.29703 \\
\hline & $41-60$ & 28 & 0.02083 & -0.05672 \\
\hline \multirow{6}{*}{ Warehouse } & $1-20$ & 164 & 0.95563 & -0.72264 \\
\hline & $21-40$ & 297 & 0.86027 & -0.58155 \\
\hline & $41-60$ & 210 & 0.64652 & -0.31613 \\
\hline & $61-80$ & 142 & 0.59371 & -0.26207 \\
\hline & $81-100$ & 82 & 0.71902 & -0.14824 \\
\hline & $101-120$ & 60 & 0.83622 & -0.20296 \\
\hline \multirow{6}{*}{ Workshop } & $1-20$ & 653 & 0.97972 & -1.15876 \\
\hline & $21-40$ & 1,036 & 0.95246 & -1.09146 \\
\hline & $41-60$ & 698 & 0.92431 & -1.02215 \\
\hline & $61-80$ & 360 & 0.73135 & -0.73724 \\
\hline & $81-100$ & 220 & 0.89056 & -0.54848 \\
\hline & $101-120$ & 138 & 0.73250 & -0.27964 \\
\hline
\end{tabular}

of the exponent was positive correlation with the probability of occurrence of small-scale fires. It was negative correlation for large-scale fires. The value decreased with the fire fighting time increasing, which indicated that the fire control ability became poor for long fire fighting time.

Correspondence analysis concluded that the fires occurred at market place, public amenities, restaurants and hotel tended to drop the range with short fire fighting time and small burned area. However, workshop and warehouse fires dropped to the range with large burned area and long fighting time. 
The probability distribution of burned area with different fire sites also followed power law. Furthermore, with the same fire fighting time, the exponent of power function was different, which also indicated the level of fire control ability. In addition, decrease rate of the exponent was also different. With the fire fighting time increasing, the efficiency for dwelling fires decreased fastest, followed by public place, market place and workshop. The efficiency at warehouse decreased slowest. The results can be taken as a reference for fire rescure at different places.

In fact, the correlation between fire fighting time and fire loss could also be affected by many factors, like the local weather, economy, population density, and so on. The climate change and economic development both are granger cause of fire loss, and the response sensitivity of climate factor in fires is stronger than that of economic factor in fires (Zheng 2012). In this paper, we focus on discussion the correlation between fire fighting time and fire loss, and will further analysis the effect of these factors on the correlation between fire fighting time and fire loss.

\section{Acknowledgements}

This work was sponsored by the National Basic Research Program of China (Grant No. 2012CB719705-05), the Funds for International Cooperation and Exchange of the National Natural Science Foundation of China (Grant No. 51120165001), the Major Research Plan of the National Natural Science Foundation of China (Grant No. 91024027), and the Fundamental Research Funds for the Central Universities (Grant No. WK2320000020). The Fire Bureau of Jiangxi Province has provided with the complete data and resources. On behalf of the crew, we give our sincerely appreciation to them.

\section{References}

Barnett, C. R. 1984. Pilot fire load survey carried out for the New Zealand Fire Protection Association. MacDonald Barnett Partners, Auckland.

Beh, E. J.; Lombardo, R.; Simonetti, B. 2011. A European perception of food using two methods of correspondence analysis, Food Quality and Preference 22(2): 226-231. http://dx.doi.org/10.1016/j.foodqual.2010.10.001

Cakir, H. I.; Khorram, S.; Nelson, S. A. C. 2006. Correspondence analysis for detecting land cover change, Remote Sensing of Environment 102(3-4): 306-317.

Challands, N. 2010. The relationships between fire service response time and fire outcomes, Fire Technology 46(3): 665-676. http://dx.doi.org/10.1007/s10694-009-0111-y

Chow, C. L.; Chow, W. K. 2009. Fire safety aspects of refuge floors in supper tall buildings with computational fluid dynamics, Journal of Civil Engineering and Management 15(3): 225-236. http://dx.doi.org/10.3846/1392-3730.2009.15.225-236

Cyras, P.; Griskevicius, M. 2001. Analysis of fires and rescue work in Lithuania, Statyba 7(3): 254-261.

Cyras, P.; Griskevicius, M.; Jaras, A. 1999. The analysis of fires and rescue operations in Lithuania, Statyba 5(2): 141-147.

Diana, M.; Pronello, C. 2010. Traveler segmentation strategy with nominal variables through correspondence analysis, Transport Policy 17(3): 183-190.

http://dx.doi.org/10.1016/j.tranpol.2010.01.005
Fontana, M.; Favre, J. P.; Fetz, C. 1999. A survey of 40,000 building fires in Switzerland, Fire Safety Journal 32(2): 137158. http://dx.doi.org/10.1016/S0379-7112(98)00034-4

Holborn, P. G.; Nolan, P. F.; Golt, J. 2004. An analysis of fire sizes, fire growth rates and times between events using data from fire investigations, Fire Safety Journal 39(6): 481-524. http://dx.doi.org/10.1016/j.firesaf.2004.05.002

Holborn, P. G.; Nolan, P. F.; Golt, J.; Townsend, N. 2002. Fires in workplace premise: risk data, Fire Safety Journal 37(3): 303-327. http://dx.doi.org/10.1016/S0379-7112(01)00055-8

Jacques, B. 1993. Perturbational aspects in correspondence analysis, Computational Statistics \& Data Analysis 15(4): 393410. http://dx.doi.org/10.1016/0167-9473(93)90172-P

Lu, L.; Chen, P.; Zhu, J. P.; Satoh, K.; Wang, D. Y.; Wang, Y. L. 2013a. Correlation between fire attendance time and burned area based on fire statistical data of Japan and China, Fire Technology. http://dx.doi.org/10.1007/s10694-012-0306-5

Lu, S.; Liang, C. J.; Song, W. G.; Zhang, H. P. 2013b. Frequency-size distribution and time-scaling property of high-casualty fires in China: analysis and comparison, Safety Science 51(1): 209-216. http://dx.doi.org/10.1016/j.ssci.2012.07.001

Ramachandran, G. 1972. Extreme value theory and fire losses: further results. Fire Research Note 910, Fire Research Station, Borehamwood.

Ramachandran, G. 1975. Extreme order statistics in large samples from exponential type distributions and their application to fire loss, in G. P. Patil, S. Kotz, J. K. Ord (Eds.). Statistical distributions in scientific work. Dordrecht: D. Reidel 2, 355-367. http://dx.doi.org/10.4324/9780203476123

Ramachandran, G. 1998. Economics of fire protection. Taylor \& Francis.

Robertson, A. F.; Gross, D. 1970. Fire load, fire severity and fire endurance. American Society for Testing and Materials.

Sardqvist, S.; Holmstedt, G. 2000. Correlation between firefighting operation and fire area: analysis of statistics, Fire Technology 36(2): 109-130. http://dx.doi.org/10.1023/A:1015450308130

Shi, W. X.; Ji, J.; Sun, J. H.; Lo, S. M.; Li, L. J.; Yuan, X. Y. 2013. Experimental study on influence of stack effect on fire in the compartment adjacent to stairwell of high rise building, Journal of Civil Engineering and Management 20(1): 121-131. http://dx.doi.org/10.3846/13923730.2013.802729

Shpilberg, D. C. 1977. The probability distribution of fire loss amount, Journal of Risk and Insurance 44(1): 103-15. http://dx.doi.org/10.2307/251860

Song, W. G.; Zhang, H. P.; Chen, T.; Fan, W. C. 2003. Power-law distribution of city fires, Fire Safety Journal 38(5): 453465. http://dx.doi.org/10.1016/S0379-7112(02)00084-X

Sourial, N.; Wolfson, C.; Zhu, B.; Quail, J.; Fletcher, J.; Karunananthan, S.; Bandeen-Roche, K.; Béland, F.; Bergman, H. 2010. Correspondence analysis is a useful tool to uncover the relationships among categorical variables, Journal of Clinical Epidemiology 63(6): 638-646. http://dx.doi.org/10.1016/j.jclinepi.2009.08.008

Sunil, K.; Rao, C. V. S. K. 1995. Fire load in residential buildings, Building and Environment 30(2): 299-305. http:// dx.doi.org/10.1016/0360-1323(94)00043-R

Wei, G. 2009. Analysis on the distribution regularity of fire load in different function buildings. Dissertation. University of Science and Technology of China.

Zheng, H. Y. 2012. Macroscopical influences of economic development and climate change on urban fire spatial-temporal variations in China: $\mathrm{PhD}$ thesis. Nanjing University. 


\section{Appendix}

Figure 8 showed the proportion of the data set of all fires used at each stage of this analysis.

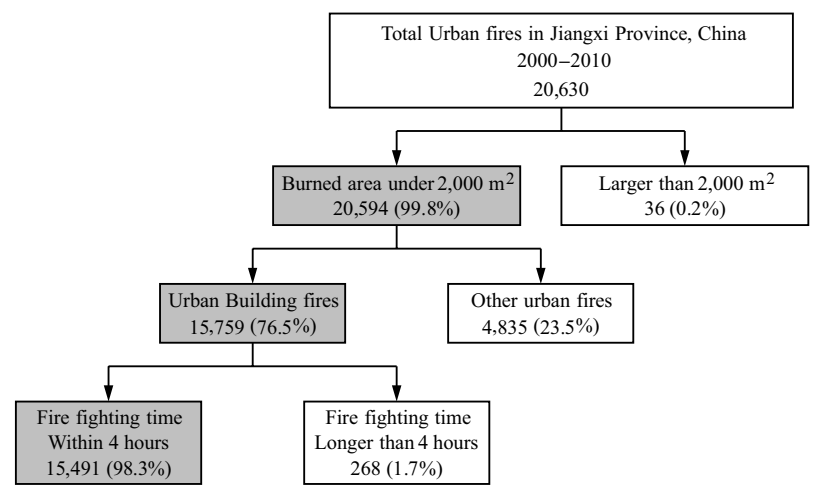

Fig. 8. Proportion of the data set in Jiangxi Province, China

\section{Nomenclature}

$t_{f}$ - Fire fighting time (min), the difference between extinguish time and reach time;

$N$ - Fire fighting time interval, $N=1,2,3 \ldots 12$;

$x_{c}$ - Lognormal distribution expectations (min);

$y_{0}$ - Coefficient of lognormal distribution;

$R^{2}$ - Fitting relation coefficient;

$A(N)$ - Coefficient of the burned area distribution law;

$B(N)$ - Coefficient of the burned area distribution law;

$X$ - Discrete random variable of the burned area $\left(\mathrm{m}^{2}\right)$;

$x_{i}$ - The possible values of $\mathrm{X}\left(\mathrm{m}^{2}\right), i=1,2,3 \ldots \ldots .2,000$.

Greek symbols

$\omega$ - Coefficient of lognormal distribution.

$$
\begin{aligned}
& \text { Subscript } \\
& \quad f \text { - fire fighting; } \\
& \text { c - average value; } \\
& 0 \text { - original value; } \\
& i \text { - discrete value. }
\end{aligned}
$$

Deyong WANG. He is a doctor student of University of Science and Technology of China from September 2010 to present. His research interest includes fire data analysis and emergency management.

Lu LU. She is a postgraduate of University of Science and Technology of China from 2010 to 2013. Her research interest is fire data analysis.

Jiajie YAO. He is a doctor student of University of Science and Technology of China from September 2012 to present. His research interest includes fire data analysis and emergency management.

Jiping ZHU. He is an associate professor of State Key Laboratory of Fire Science, University of Science and Technology of China, and is also a life member of International Association of Fire Safety Science. He received his PhD degree in Fire Safety Engineering from University of Science and Technology of China in 2004. His main research interests include urban fire risk analysis, experimental study and computer simulation of forest fire, GIS-based fire management decision-making system and dynamic assessment model of unconventional emergency response procedures.

Yunlong WANG. He is a master student of University of Science and Technology of China from September 2011 to present. His research interest includes Statistical rules for fire data and hybrid evacuation considering elevators in super-high buildings.

Guangxuan LIAO. He is a professor of State Key Laboratory of Fire Science, University of Science and Technology of China. He is also director of Suzhou Key Laboratory of Urban Public Safety, Suzhou Institute of USTC. His main research interests include fire suppression technology and application, fire dynamics and simulation, public safety emergency management and decision making. 